\title{
Finding the right RoPax vessel size and freight price. A cost and mode choice model
}

\author{
Pau Morales Fusco \\ Senior Researcher, CENIT - Centre d'Innovació del Transport \\ Marc Grau Sala \\ UPC - Universitat Politècnica de Catalunya \\ Sergi Saurí Marchán \\ Director, CENIT - Centre d'Innovació del Transporty
}

\section{SUMMARY}

Motorways of the sea operated as RoPax services are natural competitors with only-road freight haulage transportation. Cost, time and quality perceived are the determinants that make transporters and shippers use one route or another.

This research considers the role that shipping companies and their ship deployment and pricing strategy have in the equation, as incentives for modal shift from road to sea.

A model of the ships and transporter costs is developed considering different business models for the transporter (accompanied versus unaccompanied cargo) followed with a discrete choice model that, once calibrated, allows to test the influence that variables such as frequency, ship size and commercial speed might play into the competitiveness of a shipping line. As a result, different pricing strategies for the shipping line are developed and the characteristics of the optimal shipping line for each of them are found, to either maximize the profit of the shipping company or the modal shift.

\section{INTRODUCTION}

Multimodal transportation integrating a Motorways of the Sea/Short Sea Shipping (MoS/SSS) link has been widely studied as an alternative to road door-to-door transportation. The main approaches being assessing the determinants behind transportation choice, mainly from an operational point of view focused on a specific corridor either in research papers or projects (Baird, 2007; Castells Sanabra, 2009; d Este, 1992; Perakis and Denisis, 2008).

Most studies addressing SSS and MoS are oriented to study the feasibility of new lines when competing with other means of transportation (specially road) either studying the driver factors behind mode choice or assessing environmental savings achievable with the modal shift. Especially in the later, given the practical nature of feasibility and competitiveness assessments, the analysis is usually applied to specific corridors or applied cases (d Este, 
1992; Perakis and Denisis, 2008). To prove the statement, public funded projects studying the feasibility of specific MoS corridors and providing insights on how to assess the competitiveness of this kind of chains are even more frequent than their scientific paper counterpart. Projects like EMMA, COREM, INSPIRE, IPSI (4th EC framework program), D2D or REALISE (5th EC framework program) were aimed to that topic (Castells Sanabra, 2009).

Supply chains with a SSS/MoS link can be competitive in terms of door-to-door cost and time when compared to the only road chains (Bernetti et al., 2002; Saurí and Spuch, 2010). However due to the less reliable behavior (according to shippers perception) and flexibility along with the increase in complexity of the chain, shippers do not seem predisposed to leave the only road option unless there is a significant decrease in terms of cost (or time) when taking the "SSS option" (Feo et al., 2011; Paixão Casaca and Marlow, 2009). Since the maritime leg accounts for the highest internal cost of the intermodal transportation chain, the profit percent the shipping company applies to the freight fare is critical to the SSS competitiveness regarding the alternative supply chains available.

Pricing in MoS lines differs from ocean shipping in the demand's elasticity. The traditional overall low elasticity of the later contrasts with the elasticity of MoS, where SSS competes directly with road transportation and where the cost of backshift from SSS to road is negligible for the transporter (DG Move, 2015). This is especially true for the accompanied case where a substantial difference in the necessary pool of transport units does not exist (Morales-Fusco et al., 2012).

This paper conveys what might be the most appropriate pricing strategy for a regular RoPax shipping line taking into account the demand's elasticity to tariff, the ship's cost structure and the requirements and cost implications of each cargo format transported. In that sense, two optimal pricing strategies are being considered: fares for a given shipping line already on operation and fares for a line in its planning stage where, the optimal size of the vessel can be determined as well.

The paper is laid out as follows: firstly, an overview of on pricing in shipping lines and discrete choice models applied to SSS lines is provided; secondly, the scenarios considered are introduced together with the database of maritime traffic between Spain and Italy; in third place the methodology applied is introduced; later on, the results obtained are given and discussed and; finally, some conclusions are provided.

\section{PRICING IN SHIPPING LINES}

When referring to pricing strategies related to the maritime world, literature reviews are mainly focused on port pricing strategies. Shipping line pricing, however, is not a usual 
topic. Certainly, there are works that try to determinate the relationship between freight rates charged and economic determinants, that is, they do not establish a tariff strategy, and rather give a descriptive way to predict tariffs behaviour in the future (Alizadeh and Talley, 2011).

From a theoretical perspective, tariffs should equal short-run marginal costs; however, this is only true in a perfectly free economy or in an efficient socialist economy. In fact, this is the pricing system the EC advocates for in all transport services (Commission of the European Communities, 2001).

Pricing in liner shipping used to be dominated by the conference system. However, such agreements do not longer apply to traffic within Europe since its prohibition as consequence of the repeal of Council Regulation 4056/86 and within the United States of America (USA) since the passage of the Ocean Shipping Reform Act (OSRA) which has made such agreements anecdotic, at most (Acciaro, 2011; Fusillo, 2006). Nowadays, the most usual pricing system in liner shipping is what is commonly referred to as service contracts where fares are agreed between shipper and shipping company after some negotiation (Marlow and Nair, 2008). Although carriers may publish their tariffs, rarely those are the ones applied in practice with exception maybe of the occasional shipper.

The traditional forms of price discrimination since the conference system are by shipment, shipper and commodity (Jansson and Shneerson, 1987). The final fares come from the negotiation game within shipper and carrier. Shipping companies aim for a 'what the traffic can bear' charging system, taking advantage of the low elasticity of ocean transportation to freight rates, which in turn is counterbalanced by the fluctuations in demand leading to seasonal variations in tariffs in order to smooth demand over the year (or week) or applying discounts to bulk customers, serving small ones only if some capacity is left. As Acciaro (2011) points out, this has two justifications: bulk customers tend to stabilize the demand and their order usually arrive before the occasional small shippers and those might be more difficult to be accommodated.

However, MoS shipping lines system will potentially behave differently. The cost of switching from RoRo (the most common kind of ship used for MoS connections) to road transportation (modal back shift) is negligible and the flexibility that road transportation offers is currently not comparable to the usual shipping lines (DG Move, 2015). The MoS market is likely to behave as the bulk system pointed by Acciaro but, given the characteristics of what is being offered, with a more prevalent role of the small costumers taking place.

Assessing the negotiation game between provider and consumer of the service (transporter or shipper) is out of the scope of this paper. Instead, a fixed rate that discriminates by kind of cargo (full truck, with driver included, versus trailer) is the pricing system considered. Considering a homogenous pricing system, it is possible to examine the effect of price over transportation choice, taking the whole current demand as a whole and without entering in 
the discussion of the prevalent heterogeneity within the demand and their different negotiation power.

\section{CHOICE MODELS APPLIED TO SSS}

The contributions from the existing literature specifically dealing with modal choice applied to maritime transportation competing with road transportation are few and most of them are already included in Feo-Valero et al. (2011) a bibliographical assessment of Value of Time (VOT) considerations in freight transportation discrete choice models.

Most references on the topic, are in fact, participated by Feo-Valero and spanning from 2003 to 2015. In the series of papers, the authors discussed the best approach to identify the attributes behind mode shifts from road to MoS lines, and provided weighted values for the parameters of several Logit models to assess the shipper's choice processes.

After a first approach, the authors built an Adaptive Stated Preference database obtained from interviewing freight forwarders, since forwarding was usually subcontracted in Spain (Espino et al., 2007). The authors identified significant variations in the Value of Time (VOT) observed depending on the origin (Spanish province) and probably the nature of the cargo. In fact, in a later paper (Garcia-Menendez and Feo-Valero, 2009), using a revealed preferences database, some bias towards the road option was found with more valuable cargo and for freight forwarders. Additionally, besides the typical attributes of cost, time and reliability that appeared in the first papers, other attributes were found to be significant in the modal choice: larger road distances play in favor of SSS and the size of the shipment benefits road since a "lorry's larger cargo capacity is an advantage" (sic) towards a container counterpart. This would not be the case for RoRo/RoPax shipments (considered in this chapter), where the ITU (Intermodal transport unit) would have the same size. Afterwards, the authors produced a comprehensive assessment of the existing literature in terms of Freight Value of Time (FVOT) (Feo-Valero et al., 2011). The paper provides a good overview of the different approaches and the diversity of attributes considered and methodologies as well as FVOT values, depending on the country, cargo, transportation mean, cargo, etc.

More references on mode choice including a MoS chain include the one from Bergantino and Bolis (2004), in fact the first reference to introduce RoRo as an alternative by itself competing with road. It used an ASP database to which it applied a Tobit model instead of the typical Logit, considering four variables: cost, time, frequency and reliability. Variables reliability and frequency were found to have a threshold after which they did not affect the competitiveness of the RoRo option whereas cost and time were considered all along (hence, the Tobit model). Besides that, and although other authors stated it otherwise (GarciaMenendez and Feo-Valero, 2009), no bias towards road was found. The lack of bias could be caused by the good knowledge of the maritime mode from the companies consulted and 
the small size of the sample ( 7 companies), as stated by the authors of the paper.

Russo and Chilà (2007) also considered the feasibility of a high speed RoRo line (peak speed of 38 knots), in this case addressing two time-sensitive industrial sectors (perishables and industrial manufactured commodities). After applying a multinomial Logit to the existing demand (no disaggregate database used), a simple cost model was built to assess the best speed to be deployed. The authors concluded that there was room for high speed RoRo connections due to the reduction in transit time. However, the model used some unlikely assumptions, like full cargoes, non-empty returns, an unlikely bunker consumption progression with vessel speed, and other which may have effects on the findings of the paper.

\section{METHODOLOGY}

\subsection{Starting hypothesis - scenarios definition}

A regular shipping line operated with RoPax ships competing with an only-road alternative is considered. Three alternatives of freight movement are taken into account: road only, road combined with full trucks inside the ship and road combined with driverless units (platforms or trailers).

Costs and times for the three alternatives will be calculated with an updated version of the methodology laid out in Morales-Fusco et al., (2012) as found in (Grau Sala, 2015). To calculate the cost of the shipping link an updated version of the methodology by Saurí and Spuch (2010) will be used.

Additionally, since the cargo can travel with and without drivers (RoPax) ships, the relationship between DWT, GT and capacity (linear meters) obtained in the paper, has been remade to include passenger capacity as follows, after considering a database with the ships from 50 of the busiest RoRo and RoPax shipping lines, and disregarding lines oriented to ferry services.

$$
\begin{gathered}
G T=431.3+8.321 L+9.188 P-1.566 \cdot 10^{-3} P^{2} \quad(R=0.60) \\
D W T=2177+3.979 L-6.257 P+1.645 \cdot 10^{-3} P^{2} \quad(R=0.65)
\end{gathered}
$$

\subsection{Demand considerations}

The role that local distance (distance to the ports of call of the MoS being assessed and referred to as $\delta$ ) and total road distance $\left(L_{i j}\right)$ play on the competitiveness of a supply chain with a MoS leg is relevant for the calculation of the cost and time associated to each business strategy. Additionally, demand volumes could vary depending on the time of the year (seasonality or even day of the week) or not be fully equilibrated in both directions. To reflect this, some overcapacity, $\chi$ factor is to be used, to express that is virtually impossible to ensure 
full occupation of the maritime link all year long.

Given both considerations, the demand using a certain business model (transport alternative) should be described as:

$$
D_{k}=D \int_{\delta} \int_{L_{i j}} d\left(\delta . L_{i j}\right) p^{k}\left(\delta . L_{i j}\right)
$$

With $D$, the total demand of the hinterland considered, $D_{k}$, the demand for the given freight alternative, $d$, the percentage of the demand at a given distance ( $\delta$ and $L_{i j}$ ) and $p^{k}$ the proportion of the demand that would use the transportation alternative $k$.

$D_{k}, D$ and $d$ are obtained from current statistics observatories whereas $p^{k}$ is to be obtained by means of a disaggregate model (in this case a Logit one) that considers all the parameters playing a role in the mode choice by the transporter.

\subsection{Building the model. Demand database}

The database used registers all freight transport movements between Spain and Italy in 2012, discriminating by, main mode used, province and industrial sector. It was constructed combining data from the Spanish Office of Customs and Excise, AEAT, found in Solsona (2014) with the registers from the Italian Statistics Institute, ISTAT, taking the province as unit of measure, resulting in Fig 1.
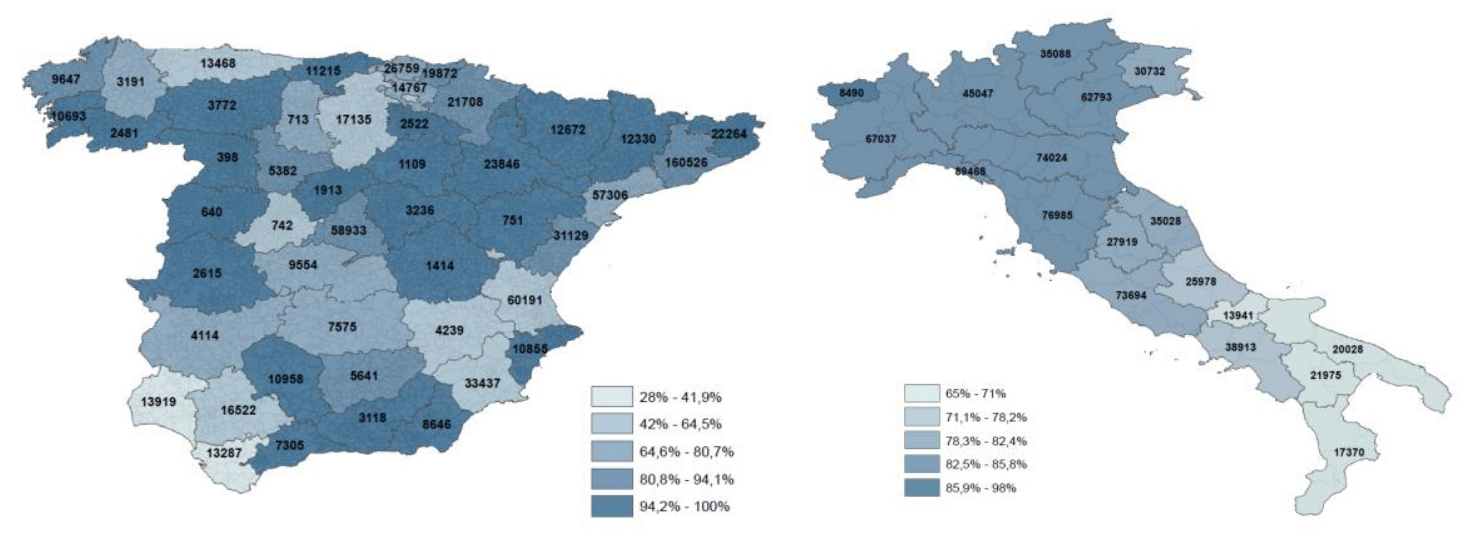

Fig 1. Total volume (tonnes) of road and MoS traffic between Spain and Italy (both directions) by province for 2012

Since the complete O-D pairing table is not known nor the specific MoS route used among the existing ones, a mathematical programing problem was solved to do the assignation. To start with, a simplified - taking only the physical parameters - version of the utility formula from Garcia-Menendez and Feo-Valero (2009) was calculated for each pairing and alternative. That is, using the updated formulas from Morales-Fusco et al. (2012) and Saurí and Spuch (2010) to calculate distances, times and costs assessed with the parameters from Garcia-Menendez and Feo-Valero (2009) for 47 times 18 O-D pairings and 15 alternatives 
in each ( 1 corresponding to the road option and two for each of the 7 possible maritime links).

With the utility values, a mathematical programming problem was solved using Simplex (with the software CPLEX Optimizer by IBM) where the demand is to be assigned to the OD matrix with the goal to maximize the overall utility and subject to the current picture in terms of use for each maritime link (differentiating accompanied from unaccompanied cargoes) and volumes departing and arriving from each of the provinces considered. For simplifying purposes import and export movements are considered altogether.

As a result, a distribution of the cargoes among all origins and destinations was obtained, reassembling the real picture, or at least, being an optimized version of it, as provided in Fig 2.

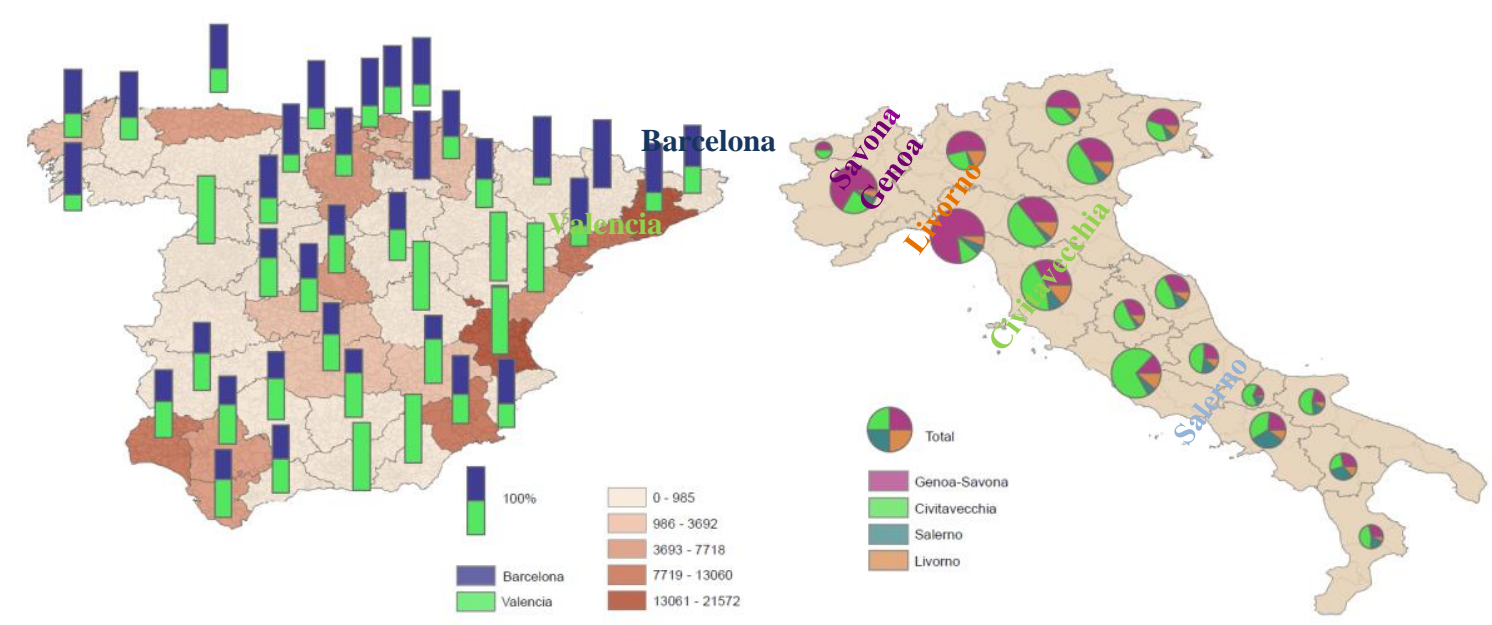

Fig 2. Distribution among ports of departure/arrival according to the province sending/receiving the cargo and, in the Spanish case, volume of cargo sent by MoS links

To ease the tariffs optimization process from the next chapter, demand is taken as following a certain probability function depending on, $L_{i j}$, the road distance between each Spanish province $i$ and Italian province $j$ and average distance, $\delta$, to the port of reference. The better fit was found with a bivariate normal distribution with a correlation value of the two variables, $\rho=0.52$, with the parameters from Table 1 :

\begin{tabular}{|c|c|c|c|}
\hline Variable & $\begin{array}{c}\text { Mean } \\
\text { (normal) }\end{array}$ & $\begin{array}{c}\text { Standard desv. } \\
\text { (normal) }\end{array}$ & p-value $($ K-S) \\
\hline$L_{i j}$ & 1550.19587 & 408.44665 & 0.6964 \\
\hline $\boldsymbol{\delta}$ & 416.698274 & 184.965677 & 0.1281 \\
\hline
\end{tabular}

Table 1. Goodness-of-fit tests of the demand distribution with $L_{i j}$ and $\delta$

\subsection{Logit model calibration}

To avoid the effect of hierarchical layers and its calibration (nested logit) a simple multinomial logit with road competing against a current sea link is being considered. Therefore, potential distribution is taken as road versus sea only (with all alternatives) for a 
given pair of ports. This would be two times detrimental for the competitiveness of any changes to the sea link being considered since: i) no catchment from other maritime lines is considered after the improvement of the line (smaller potential demand) and ii) the resulting parameter values from the logit distribution will be more detrimental towards the sea link since the amount of observations from the sample being considered (total existing demand) is, de facto, biased towards the road (more observations in \% than in the real case).

The model was calibrated considering the line Barcelona-Civitavecchia (6 departures per week) and the demand (and its characteristics) obtained from the previous section. To build the model, cost and transit time were taken as alternative specific, whereas local (average distance to the port) and road distance were common to all alternatives considered and, therefore, evaluated differently depending on the alternative to be used, as are the constant values (dummies) associated to either kind of sea maritime connection. After a first iteration, local distance was found to not be significant according to the t-test, and therefore dumped, resulting in the set of parameters and attributes provided in Table 2.

\begin{tabular}{|c|c|c|c|c|c|}
\hline Coefficient & Estimate & $\begin{array}{c}\text { Standard } \\
\text { Error }\end{array}$ & t-value & $\operatorname{Pr}(>|t|)$ & Signif. \\
\hline Constant $(\mathbf{A C})$ & -4.2243 & 0.28015 & -13.2937 & $<2.2 \mathrm{e}-16$ & $* * *$ \\
\hline Constant $(\mathbf{N A})$ & -6.1206 & 0.2999 & -20.4085 & $<2.2 \mathrm{e}-16$ & $* * *$ \\
\hline Cost $\left(\boldsymbol{C}_{\text {trip }}\right)$ & -0.0016672 & 0.00014444 & -11.5424 & $<2.2 \mathrm{e}-16$ & $* * *$ \\
\hline Transit time $\left(\boldsymbol{t}_{\boldsymbol{t}}\right)$ & -0.010852 & 0.0059461 & -2.8250 & 0.038 & $*$ \\
\hline Land distance $\left(\boldsymbol{L}_{i j}\right)$ - AC & 0.00034547 & 0.00015744 & 2.1942 & 0.02822 & $*$ \\
\hline Land distance $\left(\boldsymbol{L}_{i j}\right)$ - NA & 0.00091143 & 0.001578 & 7.0432 & $1.879 \mathrm{e}-12$ & $* * *$ \\
\hline
\end{tabular}

Likelihood ratio test $:$ chisq $=642.1$ (p.value $=<2.22 e-16)$

Table 2 - Multimodal logit estimated values for the road vs Civitavecchia-Barcelona MoS case, excluding local distance

All values have the expected sign and return a value of time, VOT, of $6.51 € / \mathrm{h}$ and ITU, on the same range of the values observed in the literature (Feo-Valero et al., 2011). The role of the alternative-exclusive parameters is similar for both maritime alternatives, being large road distances more beneficial for the driverless case, whereas, both modes have a, rather larger, intercept value, representing the reluctance to use the maritime link despite its performance in terms of cost and time and maybe accounting for other variables non considered at this point as well.

\section{RESULTS AND DISCUSSION}

At this point, equation 3 can be solved for any set of tariffs for the specific case studio connecting Barcelona and Civitavecchia. In fact, it is even possible to, by means of a 
sequential approximation to obtain the set of tariffs that can either maximize the benefits or minimize the global cost for the shippers as discussed in the following sections. In both cases, the optimal values were obtained by running the formulation in $\mathrm{R}$ and by means of non-linear minimization using the Newton-Raphson method (mln package).

\subsection{Tariffs for profit maximization}

Tariffs are calculated to optimize the profit for the shipping company considering the cost functions from Saurí and Spuch (2010) combined with equations 1 and 2. The results obtained are summarized in Fig 3.Fig 2

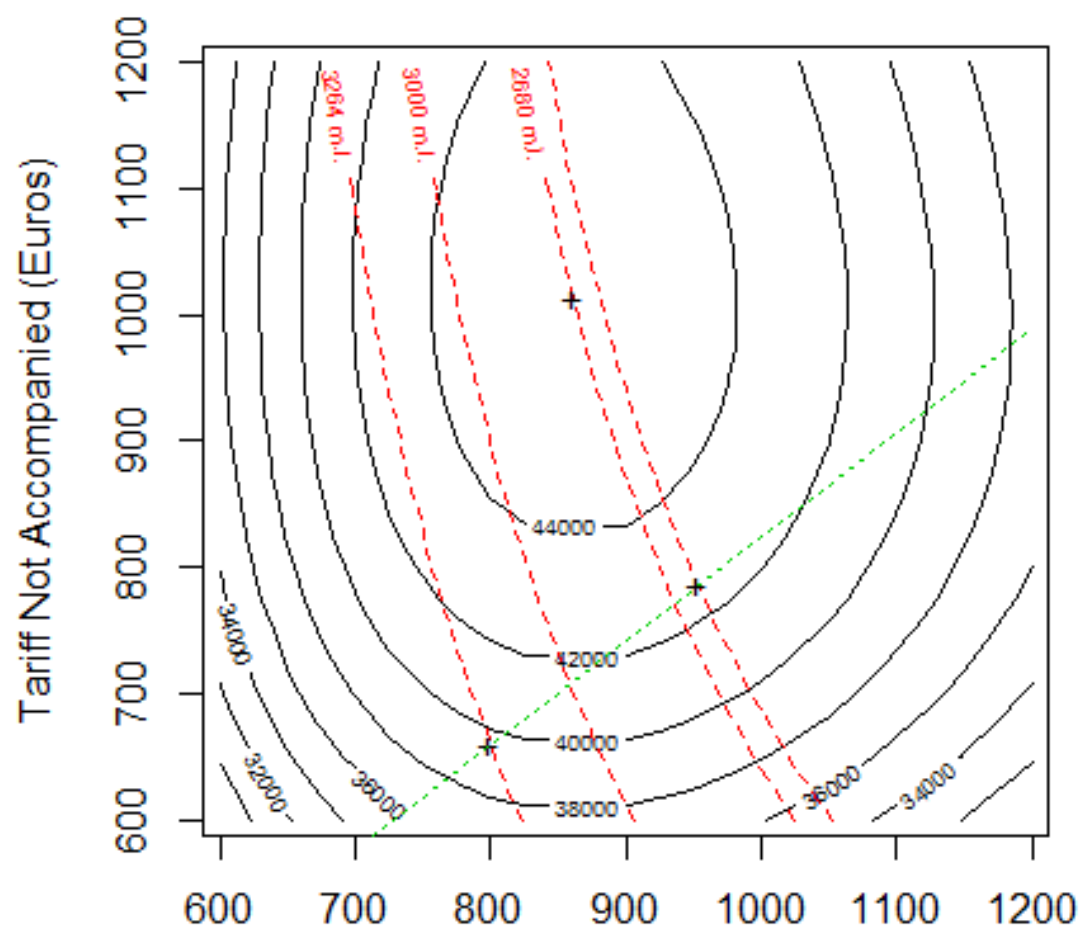

Tariff Accompanied (Euros)

\section{Fig 3. Profits and total carriage for the Civitavecchia-Barcelona MoS line with different} tariffs

It can be observed in Fig 3 that the maximum benefit (45,303 €/trip) is obtained from charging more to the non-accompanied cargo than to the accompanied one (860 vs $1014 €$ per trip), which is, at least, paradoxical, and a ship with 2680 linear meters (and room for 128 drivers). The reason for this is that the shipping company prefers accompanied cargo over driverless ITUs, therefore, just $24 \%$ of the occupied space would be used by platforms, an alternative that, as a result of the ticket price will have smaller utility than the accompanied and road counterparts but that would choose the driverless option due to the error distribution in the Logit function. Also, when considering that flows are not completely compensated (i.e. there is a percentage of empty returns, charged to the transporter), results in a de facto tariff for the accompanied option of $1011 €$ per shipment, quite similar to the unaccompanied value. 
The picture is repeated whenever the size of the ship is preset, as it can be observed as well in Fig 3 by means of the red lines. For instance, considering the optimal ship size obtained after applying the tariffs charged in 2012 in the Barcelona-Civitavecchia line (3265 linear meters and capacity for 136 drivers) it is observed that changing the tariffs to 723.5 and 944.6 would suppose a benefit increase by $8.2 \%$ while keeping the same ship occupation (in linear meters).

Nonetheless, if the current ratio of prices is enforced to be maintained, the optimal option is found to be when charging 953.3 and 786.5 for accompanied and driverless ITU, respectively and with a ship with 2305 linear meters and room for 92 passengers producing a benefit $7.6 \%$ larger than the original case, just $0.5 \%$ less than the optimal -but more difficult to explain- pricing where the driverless option was charged more than the accompanied option.

\subsection{Funding measures to promote the modal shift}

The optimal pricing scheme would be the one that maximizes the utility of the cargo shippers or, from a social point of view, the one minimizing the global generalized costs.

The first case, with the actual Logit function parameters, would result in maximizing the transport alternative with the average larger utility, that is, the road option. In fact, the tests performed, return impossible freight tariffs to force that no users opt for the maritime option, therefore maximizing the utility should not be considered as a guideline to determine the social optimal tariff. In the second case, it is necessary to include external costs to the equation and a system to relate them to the utility function values already considered, an approach to take in future research.

The effectiveness of two distinct funding measures have been assessed, considering that their perception by the transporter is the same (both affect costs/tariffs): Funding the maritime liner per ITU transported or funding directly the transporter that chooses a maritime option to carry its cargo, in line with the ecobonus system existing in Italy until the mid 2000s.

The test using the current Logit distribution and parameters and without restricting the size of the ship returns that there is small difference in the number of ITUs attracted per euro invested: 0.185 vs 0.174 ITUs/€ per the maritime company and the transporter, respectively. Both cases promote the use of bigger ships and compete against the diseconomies of scale, either by allowing to increase the tariffs and traffics when funding the transporters or by allowing to reduce tariffs (and increase traffic in consequence) when funding the maritime shipping line.

The results in Fig 4 and Fig 5 show that the shipping liner would benefit the most when funded indirectly via the transporters, since it could increase tariffs in $0.24 €$, on average, per euro given to the transporter and still increase traffic. On the other hand, $0,76 €$ of each euro 
given to the maritime liner, would be directly applied to the tariffs, charged, and the company would still increase its profit since from the new traffic attracted.
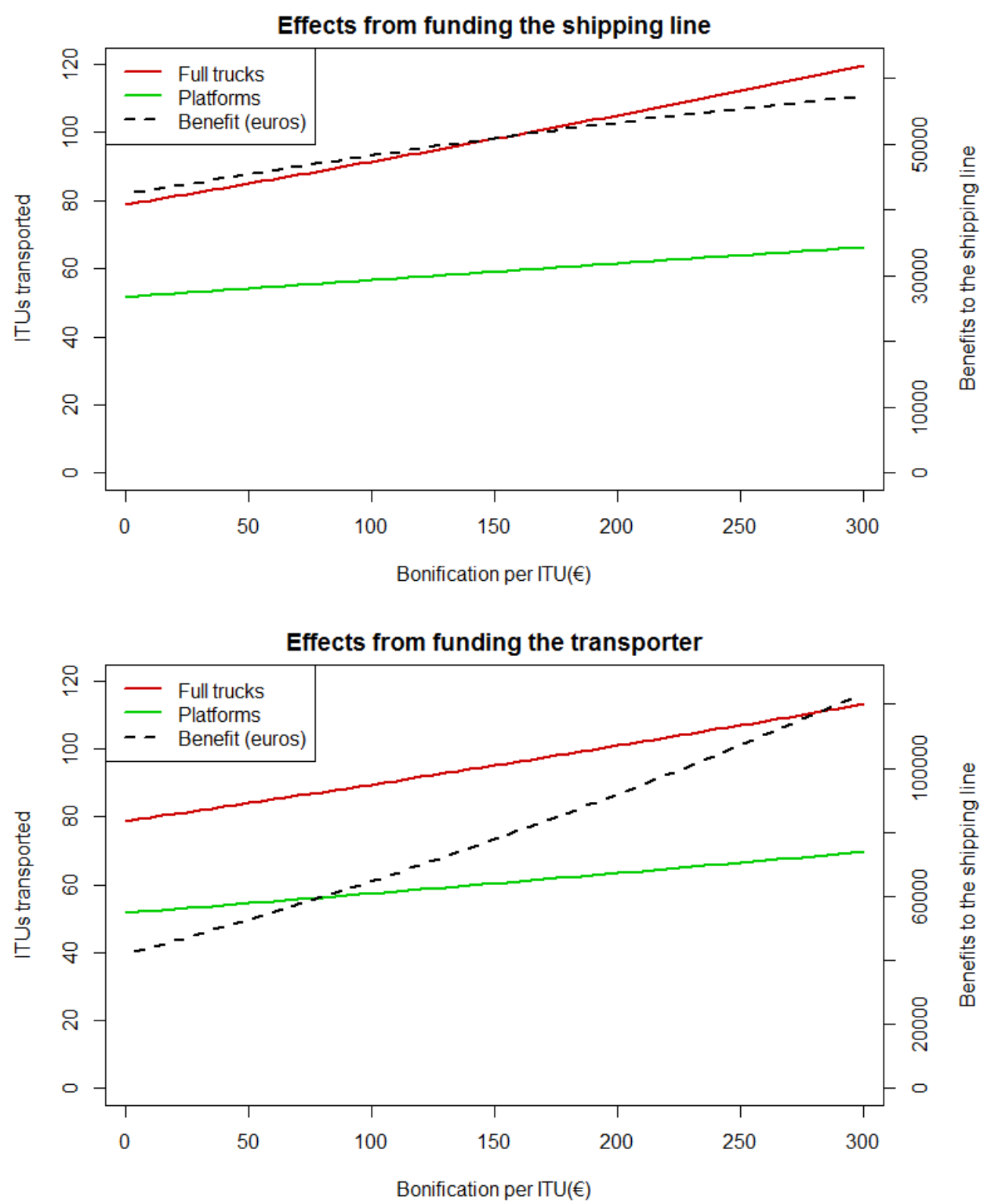

Fig 4. Demand variations from directly funding the maritime company vs funding the freight transporter and profit evolution for the shipping company

It must be kept in mind that this would be the case in a planning stage, where the size of the ship can vary. 

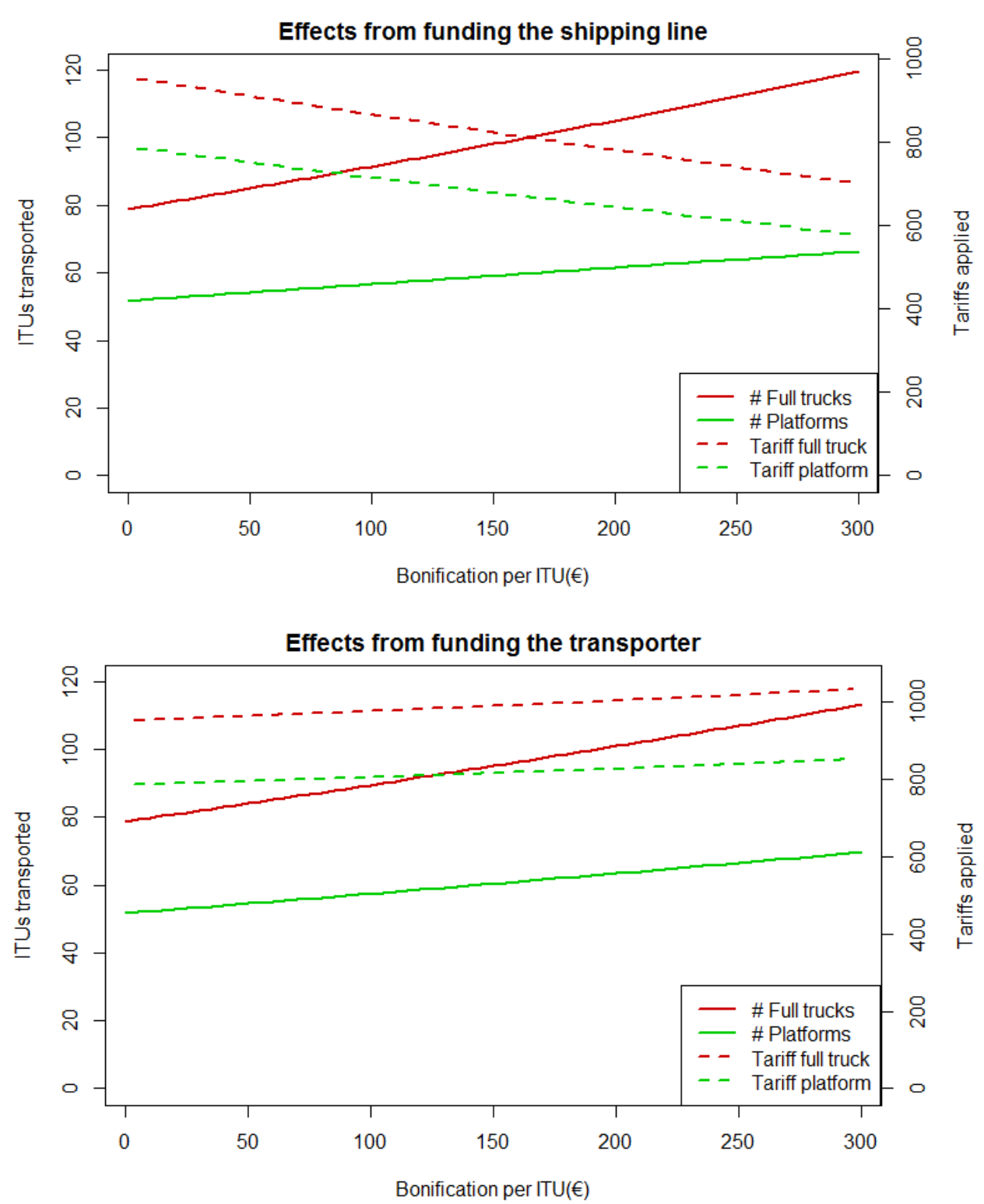

Fig 5. Demand variations from directly funding the maritime company vs funding the freight transporter and tariffs charged by the shipping company

\section{CONCLUSIONS AND FURTHER RESEARCH}

This paper conveys what might be the most appropriate pricing strategy for a regular RoPax shipping line taking into account the demand's elasticity to tariff, the ship's cost structure and the requirements and cost implications of each cargo format transported. In that sense, two optimal pricing strategies are being considered: fares for a given shipping line already on operation and fares for a line in its planning stage where, the optimal size of the vessel can be determined as well.

The paper calibrates the parameters of a discrete choice logit function based in physical quantifiable variables for the Barcelona-Civitavecchia scenario. It also proposes and updates 
the cost formula for the maritime liners from Morales-Fusco et al. (2012) to include the room for passengers in the equation and provides observations regarding the current demand structure between Italy and Spain.

A routine in $\mathrm{R}$ is built to calculate the optimal price scheme for the maritime link by means of a non-linear minimization using the Newton-Raphson method. The results obtained show that:

- The shipping company benefits the most from aiming at the accompanied transport, but only slightly, forcing the cargo to be charged at least proportionally to the deck space it occupies returns profits just $0.4 \%$ below the maximum obtained with the optimal pricing.

- The shipping line increases its profit from using smaller ships and larger tariffs due to the diseconomies of scale in RoPax ships already identified in Saurí and Spuch, (2010). In such scenario it should be beneficial to increase the number of ships on operation (and frequency) over increasing their size.

- Direct funding to the liner shipping company per unit transported is slightly more efficient for modal shift than funding to the transporter for using a MoS connection. And, in fact, the shipping company obtains larger profit if indirect funding -via the transporters- than when direct funding is being used.

Further research should encompass the effects of variations on the most sensitive elements of the cost and time formulas (bunker price fluctuation, driver driving regulations) and, more specially the effects from partially internalizing the external costs through programs such the eurovignette. The constructed framework also gives room to assess the most effective funding (or charging) scheme to reduce the global generalized costs, once the external costs of the different means of transport available, are introduced in the cost and utility calculations.

\section{REFERENCES}

ACCIARO, M. (2011). Service differentiation in liner shipping: advance booking and express services. International Journal of Shipping and Transport Logistics, 3, pp. 365-380. ALIZADEH, A.H. and TALLEY, W.K. (2011). Microeconomic determinants of dry bulk shipping freight rates and contract times. Transportation, 38, pp. 561-579.

BAIRD, A.J. (2007). The economics of motorways of the sea. Maritime Policy and Management, 34(4), pp. 287-310.

BERGANTINO, A.S., BOLIS, S. (2004). An Analysis of Maritime Ro-Ro Freight Transport Service Attributes through Adaptive Stated Preference: an Application to a Sample of Freight Forwarders. European Transport, 25-26, pp. 33-51.

BERNETTI, G., DALL'ACQUA, M., LONGO, G. (2002). Road Transport vs Ro-Ro: A modellistic approach to freight modal choice, in: European Transport Conference 2002 Proceedings. Association for European Transport (AET), Cambridge, UK.

CASTELLS SANABRA, M. (2009). Short Sea Shipping efficiency analysis considering 
high-speed craft as an alternative to road transport in SW Europe. PhD Thesis. Universitat Politècnica de Catalunya - BarcelonaTech, Barcelona, Spain.

COMMISSION OF THE EUROPEAN COMMUNITIES (2001). WHITE PAPER: European transport policy for 2010: time to decide.

d ESTE, G.M. (1992). Carrier selection in a RO/RO ferry trade Part 2. Conceptual framework for the decision process. Maritime Policy and Management, 19(2), pp 127-140. DG MOVE (2015). Analysis of recent trends in EU shipping and analysis and policy support to improve the competitiveness of Short Sea Shipping in the EU. Report.

ESPINO, R., FEO-VALERO, M., GARCÍA-MENÉNDEZ, L. (2007). Factores determinantes de la demanda de transporte de mercancías en la autopista del mar de europa suroccidental: un análisis con preferencias declaradas de la elección modal de los operadores logísticos españoles, in: XIII Congreso Chileno de Ingeniería de Transporte. Santiago, Chile.

FEO, M., ESPINO, R., GARCÍA, L. (2011). An stated preference analysis of Spanish freight forwarders modal choice on the south-west Europe Motorway of the Sea. Transport Policy 18(1), pp. 60-67.

FEO-VALERO, M., GARCÍA-MENÉNDEZ, L., GARRIDO-HIDALGO, R. (2011). Valuing Freight Transport Time using Transport Demand Modelling: A Bibliographical Review. Transport Reviews, 31, pp. 625-651.

FUSILLO, M. (2006). Some notes on structure and stability in liner shipping. Maritime Policy and Management. 33(5), pp. 463-475.

GARCÍA-MENÉNDEZ, L., FEO-VALERO, M. (2009). European Common Transport Policy and Short-Sea Shipping: Empirical Evidence Based on Modal Choice Models. Transport Reviews, 29(2), pp. 239-259.

GRAU SALA, M. (2015). Cost structure and pricing strategy for a regular RoRo shipping line. Master Thesis. Universitat Politècnica de Catalunya.

JANSSON, J.O., SHNEERSON, D. (1987). Liner shipping economics. Springer Netherlands.

MARLOW, P., NAIR, R. (2008). Service contracts-An instrument of international logistics supply chain: Under United States and European Union regulatory frameworks. Maritime Policy, 32(3), pp. 489-496.

MORAlES-FUSCO, P., SAURÍ, S., LAGO, A. (2012). Potential freight distribution improvements using motorways of the sea. Journal of Transport Geography, 24, pp. 1-11. PAIXÃO CASACA, A, MARLOW, P.B. (2009). Logistics strategies for short sea shipping operating as part of multimodal transport chains. Maritime Policy and Management, 36, pp. $1-19$.

PERAKIS, A.N., DENISIS, A. (2008). A survey of short sea shipping and its prospects in the USA. Maritime Policy and Management, 35(6), pp. 591-614.

RUSSO, F., CHILÀ, G. (2007). The High Speed Potentiality in the Motorway of the Sea : a Modal Choice Model, in: 11th World Conference on Transport Research. Berkeley, CA, USA.

SAURÍ, S., SPUCH, B. (2010). Economies of scale of ro-pax vessels in regular shipping 
lines, in: IAME Proceedings. Lisbon, Portugal.

SOLSONA, M. (2014). Impacte econòmic de la implantació de l'Eurovinyeta sobre el transport per carretera als estats perifèrics de la Unió Europea. Master Thesis. Universitat Politecnica de Catalunya. 